\title{
Horizontal stress change of energy piles subjected to thermal cycles in sand
}

\author{
Authors: C. W. W. Ng, Q. J. Ma* and A. Gunawan \\ *Corresponding author
}

\section{Information of the authors}

Corresponding author: Mr Q. J. Ma

Research student, Department of Civil and Environmental Engineering, Hong Kong

University of Science and Technology, Clear Water Bay, Kowloon, Hong Kong.

E-mail: qmaah@connect.ust.hk

Co-author: Dr C. W. W. Ng

Chair Professor, Department of Civil and Environmental Engineering, Hong Kong University

of Science and Technology, Clear Water Bay, Kowloon, Hong Kong.

E-mail: cecwwng@ust.hk

Co-author: Mr A. Gunawan

Research student, Department of Civil and Environmental Engineering, Hong Kong

University of Science and Technology, Clear Water Bay, Kowloon, Hong Kong.

E-mail: agunawan@ connect.ust.hk

$-1-$ 


\section{Abstract}

2 Horizontal stress changes of semi-floating energy piles subjected to cyclic thermal loading

3 are investigated through finite element analysis adopting the hypoplastic model. By using

4 the validated finite element model a parametric study is carried out, considering effects of

5 amplitude of thermal cycles, pile diameter, pile length and relative density of sand. It is

6 revealed that due to volumetric contraction of sand (loose or dense) at the interface under

7 temperature induced cyclic shearing, a reduction of horizontal stress occurs. The degree of

8 reduction in horizontal stress is most affected by the amplitude of thermal cycles and the

9 pile diameter.

10 Keywords: energy piles; cyclic; horizontal stress; sand. 


\section{1. Introduction}

12 Energy piles have been used to exploit the shallow geothermal energy and gained growing

13 popularity over the past few decades [1-3]. Due to some uncertainties related to the

14 thermo-mechanical performance of energy piles, increasingly more investigations have been

15 carried out. Centrifuge modelling of energy piles in saturated sand [4] and unsaturated silt [5]

16 show that antecedent thermal heating improves the ultimate bearing capacity of energy piles.

17 Full-scale field tests in sand carried out by Wang et al. [6] show that antecedent heating

18 improves the shaft resistance of energy piles. While centrifuge test results from Goode and

19 McCartney [5] show almost no effect of heating on the bearing capacity of energy piles in dry

20 sand. Thermo-elastic numerical analysis carried out by Olgun et al. [7] shows that radial

21 expansion of energy pile due to monotonic heating contributes limited increase in horizontal

22 stress.

23 For normal operating conditions, however, energy piles are subjected to thermal cycles rather

24 than monotonic heating $[1,9,11]$. Cumulative settlement behaviour was reported for

25 semi-floating energy piles under thermal cycles experimentally [8-10] and analytically by

26 modified load transfer method [11-12]. For end-bearing piles, thermal cycles only have

27 slight effect on the pile head displacement according to test results from Stewart and

28 McCartney [13]. 
29 One possible reason for the cumulative settlement of semi-floating energy piles is that when

30 energy piles experience temperature cycles there are repeated pile deformations in both

31 horizontal and vertical directions due to thermal expansion and contraction. This imposes

32 cyclic compression, extension and shearing on soil at the interface, which can result in

33 volumetric contraction of the soil [14]. Therefore, reduction of horizontal stress and shaft

34 resistance is induced according to Boulon and Foray [15]. Consequently, additional pile

35 settlement occurs to further mobilize the base resistance to compensate for the shaft

36 resistance reduction. This change of horizontal stress may be estimated by equation (1)

37 proposed by Boulon and Foray [15]

$38 \Delta \sigma_{h}=4 \delta_{h} E_{p} / D$

39 where $\delta_{\mathrm{h}}$ is the change in thickness of the interface soil layer, $E_{\mathrm{P}}$ is the pressuremeter modulus

40 of soil and $D$ is the pile diameter. This equation is derived based on the elastic cavity

41 expansion theory by assuming that the far-field soil behaves elastically. It can be readily

42 deduced that any volume change (elastic or plastic) at the interface soil layer can result in a

43 variation of horizontal stress. When used in practice, an effective pressuremeter modulus

44 should be chosen to account for the stiffness degradation with strain.

45 The objectives of this study are (1) to validate the above discussed mechanism; (2) to quantify

46 the horizontal stress change of semi-floating energy piles in sand subjected to thermal cycles 
47 via finite element analysis.

48 2. Numerical parametric study plan

49 In this study, bored concrete piles embedded in dry Toyoura sand are simulated as

50 wished-in-place piles. Two series of numerical simulations were performed to investigate

51 effects of the amplitude of thermal cycles $(\Delta T)$ and the pile diameter $(D)$. The amplitude of

52 thermal cycles and pile diameter affect the magnitude of pile deformations, and thus

53 volumetric contraction of soil at the interface [14]. For both series, three different relative

54 densities $\left(D_{\mathrm{r}}\right)$ are considered to simulate loose, medium-dense and dense sand, respectively.

55 To investigate the effects of pile length, another two series (i.e. Series 3 and 4) of numerical

56 analyses on pile length, ranging from $20 \mathrm{~m}$ to $35 \mathrm{~m}$, were carried out. For Series 3 , the pile

57 diameter is kept the same at $1.0 \mathrm{~m}$; whereas for Series 4, the pile diameter is also increased

58 from $1.0 \mathrm{~m}$ to $1.75 \mathrm{~m}$ to maintain the ratio of pile length to pile diameter $(L / D)$ equal to 20 .

59 For all the cases analyzed, the overall factor of safety is taken as 2.0 according to the failure

60 criterion proposed by $\mathrm{Ng}$ et al. [16]. Full reversal thermal cycles $( \pm \Delta T)$ are applied with

61 respect to the reference temperature. Details of the parametric study are listed in Table 1.

62 3. Numerical modelling methodology

63 3.1. Constitutive models and model parameters 
64 In order to simulate the above discussed mechanism, primary requirement of the soil

65 constitutive model is to predict the volume change of soil under cyclic shearing. To achieve

66 this purpose, the incrementally nonlinear hypoplastic model for sand developed by Niemunis

67 and Herle [17] is adopted. Niemunis and Herle refined von Wolffersdorff's model [18] by

68 introducing a small elastic range to improve the simulation of sand behaviour under cyclic

69 loading. There is no explicitly defined yield surface for the hypoplastic model, and the

70 state-dependent dilatancy of sand behaviour can be well simulated. Niemunis and Herle's

71 model needs a total of 13 parameters. All the model parameters and their definitions are listed

72 in Table 2. Model parameters for Toyoura sand are based on the calibration by Herle et al. [19]

73 and $\mathrm{Ng}$ et al. [20].

74 It should be noted that the adopted hypoplastic model cannot consider thermal effects on soil

75 [21-23]. This study only focuses on the mechanical aspect of the fully-coupled

76 thermo-mechanical soil-structure interaction problem. Heat flow and thermal effects on soil

77 behaviour are not considered. It is expected that ignoring thermal effects on soil behaviour is

78 likely to underestimate horizontal stress reduction, especially at the first heating-cooling

79 cycle, within which thermally-induced volumetric contraction of sand and normally

80 consolidated clay mainly occurs [21-23].

81 The concrete energy pile itself is assumed to behave thermo-elastically. Typical parameters 
82 for concrete used in this study are in accordance with BS EN 1992-1-2. [24]. Young's

83 modulus, Poisson's ratio, linear coefficient of thermal expansion and density are $3 \times 10^{7} \mathrm{kPa}$,

$840.2,1 \times 10^{-5} /{ }^{\circ} \mathrm{C}$ and $2500 \mathrm{~kg} / \mathrm{m}^{3}$, respectively.

85 3.2. Verification of soil constitutive model

86 To verify Niemunis and Herle's model, a series of cyclic torsional simple shear tests on

87 Toyoura sand by Shahnazari [14] was back-analyzed using the finite element software

88 Abaqus. Implementation of Niemunis and Herle's model in Abaqus is realized by Gudehus et

89 al. [25] through the user subroutine UMAT.

90 Fig. 1 compares the numerical results to the experimental results of sand volume change

91 under cyclic shearing. The horizontal and vertical axes represent the void ratio $e$ and shear

92 strain $\gamma$, respectively. All four tests (a-d) show similar trends between numerical and

93 experimental results. Under cyclic shearing, there is a continuous volumetric contraction of

94 sand, but at a reduced rate. Finally, a stabilized state is reached. Quantitatively, tests b and c

95 show relatively good agreement. For test a (loose sand) the numerical simulation

96 overestimates the stabilized void ratio, while for test $d$ (dense sand) there is a slight

97 underestimation. One possible reason for the discrepancies is that the predefined lower limit

98 compression line in the hypoplastic model, which corresponds to the hypoelastic state, may

99 not be well-represented. 
100 Fig. 2 compares measured and computed shear stress $(\tau)$ - shear strain $(\gamma)$ responses for test c.

101 Although the measured increase of shear stress with an increasing number of cycles is

102 under-predicted by the model, both of them show that the soil stiffness consistently increases

103 with an increasing number of cycles.

104 Fig. 3 shows the comparison of measured and computed stress ratio $\left(\tau / \sigma_{\mathrm{n}}\right)$ versus dilatancy

$105\left(-\mathrm{d} \varepsilon_{\mathrm{v}}^{\mathrm{p}} / \mathrm{d} \gamma^{\mathrm{p}}\right)$ responses, where $\sigma_{\mathrm{n}}$ is the normal stress, $\mathrm{d} \varepsilon_{\mathrm{v}}^{\mathrm{p}}$ and $\mathrm{d} \gamma^{\mathrm{p}}$ are the plastic volumetric

106 strain increment and plastic shear strain increment, respectively. Positive volumetric strain

107 increment means contraction whereas negative is dilation. Regarding the shear strain

108 increment, it is positive for loading and negative for unloading. The computed stress ratio

109 versus dilatancy relationship shows a reasonably good agreement with the experimental

110 results [14]. Upon each reversal of loading direction, computed results show that the

111 dilatancy ratio increases first and then decreases, while immediate decrease in dilatancy ratio

112 was observed. However, this discrepancy should not affect major findings from this study.

113 The reason is what matters most for this study is the ultimate volumetric contraction of sand

114 induced by cyclic shearing. According to Fig. 1, the ultimate volumetric contraction is

115 simulated reasonably well.

116 3.3. Finite element mesh

117 Fig. 4 shows the dimensions and typical finite element mesh of the model domain. The 
118 problem is modelled as axisymmetric. 4-node bilinear element CAX4 is adopted for both pile

119 and soil with the aspect ratio of mesh elements around 1.0. As can be seen from the figure, the

120 mesh adjacent to the pile (up to $2 D$ in the horizontal direction) is refined to capture nonlinear

121 soil response. The density of pile mesh, which is not shown in Fig. 4, is half that of the refined

122 soil mesh. To eliminate possible boundary effects, outer width and height of the model

123 domain are set to be 1 and 2 times of the pile length $(L)$ according to [26]. The vertical

124 displacements on bottom of the model domain and horizontal displacements on two sides of

125 the model domain are constrained [20].

126 3.4. Pile-soil interaction

127 The pile-soil interaction is modelled as hard contact in normal direction, and the Coulomb

128 frictional model is used in tangential direction. Two parameters are necessary to characterize

129 the Coulomb frictional model, the friction angle and the allowable elastic slip to fully

130 mobilize the friction angle. For bored concrete piles, the interface friction angle is assumed to

131 be the same as the soil critical state friction angle [27]. According to the interface shear tests

132 of Peng [28], the allowable elastic slip can be taken as $5 \mathrm{~mm}$ for rough surface conditions.

133 3.5. Simulation procedure

134 In the first step of numerical simulation, the equilibrium state under gravitational load is

135 established with the coefficient of lateral earth pressure taken as 0.5 [20]. In the second step, 
136 axial working load is applied and maintained constant throughout the analysis. The working

137 load is calculated as the ratio of pile ultimate bearing capacity to the factor of safety. An

138 independent run is performed to determine the pile ultimate bearing capacity based on the

139 failure criterion proposed by $\mathrm{Ng}$ et al. [16]. In the third step, 50 full reversal $( \pm \Delta T)$

140 heating-cooling cycles at constant amplitude are imposed on the pile. Temperature

141 distribution along pile length is assumed to be uniform [2, 3].

\section{4. Validation of finite element model}

143 As this study focuses on the mechanical aspect of the fully-coupled thermo-mechanical

144 problem, a pile subjected to mechanical cyclic loading was chosen to validate the finite

145 element model. Tokimatsu et al. [29] reported a centrifuge test on a pile subjected to cyclic

146 vertical loading in dry Toyoura sand with g-level of $30 \mathrm{~g}$. The model pile had a diameter of

$147 \quad 0.65 \mathrm{~m}$ and a length of $7.5 \mathrm{~m}$ in prototype. Toyoura sand was pasted on the model pile surface

148 to create a rough surface condition. The relative density of sand was $90 \%$. Displacement -

149 control loading method was adopted. The applied amplitude of pile head displacement was

150 gradually increased $(1 \%, 5 \%, 10 \%$ and $15 \%$ of pile diameter) every three loading cycles as

151 shown in Fig. 5(a). The centrifuge test was simulated to validate the finite element model.

152 Fig. 5(b) compares the experimental and numerical results (prototype) of mobilized shaft

153 resistance $\left(Q_{\mathrm{s}}\right)$ with the number of loading cycles $(N)$. The mobilized shaft resistance for 
154 compression and tension within each cycle are separately presented. It can be seen that

155 although there are some minor discrepancies between the experimental and numerical results,

156 the numerical simulation is able to capture the mobilized shaft resistance in compression as

157 well as in tension. The consistency between simulated and measured results gives confidence

158 that the finite element model developed is appropriate.

159 5. Results

160 In this section, energy pile response during thermal cycles is analyzed first, followed by

161 discussion on the horizontal stress change corresponding to the end of 50 thermal cycles. The

162 horizontal stress change under consideration represents the average value along the pile

163 length. In addition, the horizontal stress change is normalized by the initial value and negative

164 values indicate a decrease. The normalization of horizontal stress change is calculated

165 according to equation (2):

$166 \Delta \sigma_{h}=\left[\left(\sigma_{h}-\sigma_{h}^{0}\right) / \sigma_{h}^{0}\right] \cdot 100$

$167 \Delta \sigma_{h}^{50}=\left[\left(\sigma_{h}^{50}-\sigma_{h}^{0}\right) / \sigma_{h}^{0}\right] \cdot 100$

168 where $\sigma_{\mathrm{h}}$ is the horizontal stress; $\sigma_{\mathrm{h}}^{0}$ and $\sigma_{\mathrm{h}}^{50}$ are the horizontal stresses before thermal cycles

169 and after 50 thermal cycles, respectively; $\Delta \sigma_{\mathrm{h}}$ is the horizontal stress change at a given

170 thermal cycle, while $\Delta \sigma_{\mathrm{h}}^{50}$ is the horizontal stress change after 50 thermal cycles. 
171 The ultimate pile resistance, working load, ultimate shaft resistance and base resistance, and

172 mobilized shaft resistance and base resistance at working load for all the cases analyzed are

173 summarized in Table 3.

174 5.1. Energy pile response during thermal cycles

175 As the underlying mechanism is the same, one typical case is chosen to analyze the energy

176 pile response during thermal cycles. Details of the typical case are $D_{\mathrm{r}}=85 \%, D=1 \mathrm{~m}$,

$177 L=20 \mathrm{~m}$ and $\Delta T=15^{\circ} \mathrm{C}$.

178 Fig. 6 shows the change of horizontal stress $\Delta \sigma_{\mathrm{h}}$ and the normalized pile head settlement $\omega_{\mathrm{h}}$

179 against pile diameter $D$ during thermal cycles. It can be seen that within each thermal cycle

180 horizontal stress may increase or decrease due to thermal expansion or contraction of the pile

181 diameter. The overall trend with thermal cycles is a continuous reduction of horizontal stress

182 due to volumetric contraction of sand at the interface under cyclic shearing, resulting in shaft

183 resistance reduction. To compensate for the loss of shaft resistance, additional pile settlement

184 accumulates to further mobilize the base resistance, as demonstrated in Fig. 7(a).

185 Fig. 7(b) shows the evolution of shaft resistance $\left(Q_{\mathrm{S}}^{\mathrm{M}}\right)$ and base resistance $\left(Q_{\mathrm{B}}^{\mathrm{M}}\right)$ normalized

186 by the ultimate shaft resistance $\left(Q_{\mathrm{S}}\right)$ and ultimate base resistance $\left(Q_{\mathrm{B}}\right)$ (see Table 3 ),

187 respectively. What should be noted from this figure is that the mobilized base resistance

188 continues to increase with thermal cycles. One reason is due to the continuous settlement of 
energy piles. The other reason is that sand below the pile base is densified due to cyclic

190 shearing, and thus the base resistance is improved. The second point is further demonstrated

191 in the following section.

192 It should also be noted that, as thermal cycle continues, the rate of horizontal stress decrease

193 and additional pile settlement reduces. The decrease of horizontal stress approaches a

194 stabilized value and the pile head settlement levels off before the end of 50 thermal cycles as

195 indicated by the asymptotic lines in Fig. 6. The axial working load is compressive in this

196 study. Therefore, as long as the axial working load is less than the base resistance available to

197 be mobilized, eventually the pile response will stabilize at the cost of additional settlement to

198 mobilize the base resistance.

199 Fig. 8 shows the changes in horizontal stress $\left(\Delta \sigma_{\mathrm{h}}\right)$ and volumetric strain $\left(\varepsilon_{\mathrm{v}}\right)$ with thermal

200 cycles $(N)$ for soil elements adjacent to the pile shaft at different depths. Evolution of the

201 average horizontal stress change over entire pile length and the volumetric strain of one soil

202 element below the pile base are also included in this figure. It can be seen that except for the

203 soil element at $Z=20 \mathrm{~m}$, all other soil elements adjacent to the pile shaft experience

204 continuous volumetric contraction, but at a reduced rate. Correspondingly, the horizontal

205 stress decreases, but stabilizes at about $2 \%$ volumetric contraction. For the soil element at

$206 Z=20 \mathrm{~m}$, initially there is some dilation followed by continuous contraction, which leads to 
207 an increase of horizontal stress at the beginning and then a decrease of horizontal stress. The

208 average horizontal stress change over entire pile length reflects the global response and is

209 more close to that of the soil element at $Z=15 \mathrm{~m}$.

210 The soil element below the pile base (denoted by 'Base' in Fig. 8) also experiences volumetric

211 contraction, which stabilizes roughly at the $15^{\text {th }}$ thermal cycle. The enhanced base resistance

212 due to the densification of soil below the pile base explains the relatively small pile settlement,

213 despite a large reduction in shaft resistance.

214 5.2. Horizontal stress decrease after 50 thermal cycles

215 Fig. 9 shows the effect of amplitude of thermal cycles $(\Delta T)$ on the horizontal stress decrease

216 after 50 thermal cycles $\left(\Delta \sigma_{\mathrm{h}}^{50}\right)$ for three different relative densities. It can be seen that as $\Delta T$

217 increases from $5{ }^{\circ} \mathrm{C}$ to $20^{\circ} \mathrm{C}, \Delta \sigma_{\mathrm{h}}^{50}$ goes up from about $15 \%$ to almost $90 \%$. According to

218 Shahnazari [14], for the same number of cycles, cyclic shearing induced volumetric

219 contraction of sand increases with the shearing amplitude. For energy piles under thermal

220 cycles, the amplitude of cyclic shearing increases with $\Delta T$. Therefore, a larger $\Delta T$ results in a

221 larger volumetric contraction, and hence a higher reduction in horizontal stress according to

222 equation (1).

223 It can also be seen from Fig. 9 that the relationship between $\Delta \sigma_{\mathrm{h}}^{50}$ and $\Delta T$ is approximately

224 bilinear. This bilinear trend is similar to the mobilization of active earth pressure with $\delta_{\mathrm{h}}$ in 
equation (1) being the displacement driving the mobilization. As $\delta_{\mathrm{h}}$ exceeds some threshold

226 value, the mobilized active earth pressure remains relatively constant.

227 Reduction in shaft resistance of piles under cyclic axial loading has been observed both in

228 centrifuge (see Fig. 5) and field tests [30-31]. Poulos [30] reported up to 90\% reduction in

229 shaft resistance after 100 two-way loading cycles. Jardine and Standing [31] reported that

$23026-29 \%$ reduction in tension capacity occurs at a pile head displacement of $10 \%$ of pile

231 diameter.

232 Fig. 10 presents the effect of pile diameter $D$ on $\Delta \sigma_{h}^{50}$ for three different relative densities. As

233 shown in the figure, there is some increase of $\Delta \sigma_{\mathrm{h}}^{50}$ as pile diameter increases from $0.6 \mathrm{~m}$ to

$2340.8 \mathrm{~m}$. One reason is that the magnitude of shearing imposed on soil at the interface

235 increases with the pile diameter. The other possible reason is that the percentage of initial

236 mobilized shaft resistance at working load to the ultimate shaft resistance increases with the

237 pile diameter (see Table 3). According to findings from [8, 11, 12], the higher the load ratio,

238 the more significant the influence of thermal cycles on the performance of energy piles.

239 However, increasing the pile diameter larger than $0.8 \mathrm{~m}$ has little influence on $\Delta \sigma_{\mathrm{h}}^{50}$. For these

240 cases with pile diameter exceeding $0.8 \mathrm{~m}, \Delta \sigma_{\mathrm{h}}^{50}$ lies within the range from $85 \%$ to $90 \%$. This

241 trend is consistent with that shown in Fig. 9. Both the amplitude of thermal cycles and pile

242 diameter can influence the amplitude of cyclic shearing imposed on soil at the interface. For 
243 those cases with $D$ larger than $0.8 \mathrm{~m}$ and $\Delta T$ being equal to $15^{\circ} \mathrm{C}$, the value of $\delta_{\mathrm{h}}$ may exceed

244 the threshold value after 50 thermal cycles, and thus the mobilized active earth pressure

245 remains relatively constant.

246 Regarding the effect of relative density of sand, Fig. 9 shows that $\Delta \sigma_{\mathrm{h}}^{50}$ is relatively

247 independent of the relative density of sand. Similar trend can also be observed in Fig. 10

248 when the pile diameter is larger than $0.8 \mathrm{~m}$. For cases with pile diameter of $0.6 \mathrm{~m}$, it seems

249 that $\Delta \sigma_{h}^{50}$ is larger for loose sand. The possible reason may be that for loose sand the shearing

250 amplitude corresponding to $D=0.6 \mathrm{~m}$ and $\Delta T=15^{\circ} \mathrm{C}$ is large enough to get $\delta_{\mathrm{h}}$ reach the

251 threshold value after 50 cycles. While for dense sand, a larger pile diameter or thermal cycle

252 amplitude is required.

253 Fig. 11 shows the effect of pile length $(L)$ on the horizontal stress decrease after 50 thermal

254 cycles $\left(\Delta \sigma_{\mathrm{h}}^{50}\right)$. The computed results for $D=1.0 \mathrm{~m}$ (i.e. Series 3 ) show that the reduction of

255 horizontal stress is a nonlinear function of pile length. As the pile length increases from $20 \mathrm{~m}$

256 to $35 \mathrm{~m}, \Delta \sigma_{\mathrm{h}}^{50}$ decreases from about $-90 \%$ to $-30 \%$. The reason is that soil elements at greater

257 depths experience less volumetric contraction and hence more cycles are required to reach a

258 steady state as shown in Fig. 8. Results from Series 4, whereby the pile diameter is also

259 increased to keep $L / D=20$, show that $\Delta \sigma_{\mathrm{h}}^{50}$ is almost constant. This is due to that a larger pile

260 diameter leads to a larger magnitude of compression and extension in the horizontal direction 
261 for a given $\Delta T$. Therefore, more volumetric contraction and horizontal stress reduction are

262 induced. This implies that horizontal deformations of energy piles play an important role in

263 the reduction of horizontal stress.

\section{6. Conclusions}

265 This paper reports a numerical investigation of the performance of semi-floating energy piles

266 subjected to thermal cycles in sand. The study focuses on the horizontal stress change

267 resulting from sand response to cyclic shearing caused by repeated thermal expansion and

268 contraction of energy piles. Based on the study presented the following conclusions may be

269 drawn:

270 (1) During thermal cycles, repeated expansion and contraction of energy piles impose cyclic

271 shearing on soil at the interface, which can induce volumetric contraction and horizontal

272 stress decrease, resulting in shaft resistance reduction. As a consequence, additional

273 settlement occurs to further mobilize the base resistance to balance the shaft resistance

274 reduction. As thermal cycle continues, for energy piles under axial compression, the pile

275 response approaches a stabilized state eventually.

276 (2) The magnitude of shearing imposed on soil at the interface is governed by the amplitude

277 of thermal cycles and the pile diameter. For the worst case, the horizontal stress reduction after 50 thermal cycles may be up to $90 \%$. For the range of pile length studied (from $20 \mathrm{~m}$ 

of the pile length at the given ratio of pile length to pile diameter of 20 . In addition, the stiffening of soil below the pile base can contribute to reduce the additional pile settlement.

(3) For practical design of energy piles in sand, the shaft resistance reduction due to horizontal stress decrease should be considered. In addition, the resultant additional settlement to further mobilize the base resistance should also be checked.

\section{Acknowledgements}

287 The financial support provided by the Research Grants Council (RGC) of the HKSAR (grant no. GRF 617213 and 16209415), the HKUST (grant no. FP204) and the National Science

289 Foundation of China (grant no. 51378178) are gratefully acknowledged. The second author

290 appreciates greatly the HKPFS scholarship offered by the RGC.

\section{References}

[1] Brandl, H. Energy foundations and other thermo-active ground structures. Géotechnique 2006; 56(2): 81-122.

[2] Laloui, L., Nuth, M. and Vulliet, L. Experimental and numerical investigations of the behaviour of a heat exchanger pile. Int. J. Numer. Anal. Meth. Geomech. 2006; 30(8): 763-781.

[3] Bourne-Webb, P. J., Amatya, B., Soga, K., Amis, T., Davidson, C. and Payne, P. Energy 
pile test at Lambeth College, London: geotechnical and thermodynamic aspects of pile response to heat cycles. Géotechnique 2009; 59(3): 237-248.

[4] Ng, C. W. W., Shi, C., Gunawan, A., Laloui, L. and Liu, H. L. Centrifuge modelling of heating effects on energy pile performance in saturated sand. Can. Geotech. J. 2015; 52(8): 1045-1057.

[5] Goode III, J. C. and McCartney, J. S. Centrifuge Modeling of End-Restraint Effects in Energy Foundations. J. Geotech. Geoenviron. Eng. 2015; 141(8): 1-13.

[6]Wang, B., Bouazza, A., Singh, R. M., Haberfield, C., Barry-Macaulay, D. and Baycan, S. Posttemperature Effects on Shaft Capacity of a Full-Scale Geothermal Energy Pile. J. Geotech. Geoenviron. Eng. 2015; 141(4): 1-12.

[7] Olgun C. G, Ozudogru T. Y, Arson C. Thermo-mechanical radial expansion of heat exchanger piles and possible effects on contact pressures at pile-soil interface. Géotechnique Letters 2014; 4(3): 170-178.

[8] Kalantidou, A., Tang, A. M., Pereira, J. M. and Hassen, G. Preliminary study on the mechanical behaviour of heat exchanger pile in physical model. Géotechnique 2012; 62(11): 1047-1051.

[9] Ng, C. W. W., Shi, C., Gunawan, A. and Laloui, L. Centrifuge modelling of energy piles subjected to heating and cooling cycles in clay. Géotechnique Letters 2014; 4(4): 310-316.

[10] Ng, C. W. W., Gunawan, A., Shi, C., Ma, Q. J. and Liu, H. L. Centrifuge Modelling of Energy Pile - Comparative Performance: Displacement versus Replacement. Géotechnique Letters 2016; 6(1): 1-5.

[11] Pasten, C. and Santamarina, J. C. (2014). Thermally induced long-term displacement of thermoactive piles. J. Geotech. Geoenviron. Eng. 2014; 140(5): 06014003.

[12] Suryatriyastuti, M. E., Mroueh, H. and Burlon, S. A load transfer approach for studying 
the cyclic behavior of thermo-active piles. Comput Geotech. 2014; 55: 378-391.

[13] Stewart, M. A. and McCartney, J. S. Centrifuge Modeling of Soil-Structure Interaction in Energy Foundations. J. Geotech. Geoenviron. Eng. 2013; 140(4): 04013044-1-11.

[14] Shahnazari, H. Experimental investigation on volume change and shear deformation characteristics of sand undergoing cyclic loading. $\mathrm{PhD}$ thesis, The University of Tokyo, Japan. 2001.

[15] Boulon, M. and Foray, P. Physical and numerical simulation of lateral shaft friction along offshore piles in sand. Proc., 3rd Int. Conf. on Num. Methods in Offshore Piling, Editions Techrig, Paris, France, 1986. 127-148.

[16] Ng, C. W. W., Yau, T. L., Li, J. H. and Tang, W. H. New failure load criterion for large diameter bored piles in weathered geomaterials. J. Geotech. Geoenviron. Eng. 2001; 127(6): 488-498.

[17] Niemunis, A. and Herle, I. Hypoplastic model for cohesionless soils with elastic strain range. Mech. Cohes.-Frict. Mater. 1997; 2(4): 279-299.

[18] von Wolffersdorff, P. A. A hypoplastic relation for granular materials with a predefined limit state surface. Mech. Cohes.-Frict. Mater. 1996; 1(3): 251-271.

[19] Herle, I. and Gudehus, G. Determination of parameters of a hypoplastic constitutive model from properties of grain assemblies. Mech. Cohes.-Frict. Mater. 1999; 4(5): 461-486.

[20] Ng, C. W. W., Hong, Y. and Soomro, M. A. Effects of piggyback twin tunnelling on a pile group: 3D centrifuge tests and numerical modelling. Géotechnique 2015; 65(1): 38-51.

[21] Agar, J., Morgenstern, N. and Scott, J. Thermal expansion and pore pressure generation in oil sands. Can. Geotech. J. 1986; 23(3): 327-333.

[22] Di Donna A and Laloui L. Response of soil subjected to thermal cyclic loading: Experimental and constitutive study. Eng Geol. 2015; 190: 65-76. 
[23] Dalla Santa G, Galgaro A, Tateo F and Cola S. Modified compressibility of cohesive sediments induced by thermal anomalies due to a borehole heat exchanger. Eng Geol. 2016; 202: 143-152.

[24] BS EN 1992-1-2:2004. Eurocode 2: Design of concrete structures - Part 1-2: General rules-Structural fire design. BSI. 2004.

[25] Gudehus, G., Amorosi, A., Gens, A. et al. The soilmodels.info project. Int. J. Numer. Anal. Meth. Geomech. 2008; 32(12): 1571-1572.

[26] Lee, J. H. and Salgado, R. Determination of pile base resistance in sands. J. Geotech. Geoenviron. Eng. 1999; 125(8): 673-683.

[27] Loukidis, D. and Salgado, R. Analysis of the shaft resistance of non-displacement piles in sand. Géotechnique 2008; 58(4): 283-296.

[28] Peng, S. Y. Influence of stress relief due to deep excavation on capacity of pile foundations. PhD thesis, Hong Kong University of Science and Technology, Hong Kong. 2012.

[29] Tokimatsu, K., Inamura, K., Suzuki, H., Wada, M. and Mano, H. Effects of alternately cyclic vertical loading on bearing capacity and pull-out resistance of a pile with or without a wing plate. J. Struct. Constr. Eng., AIJ. 2012; 77(681): 1683-1689 (in Japanese).

[30] Poulos, H. G. Cyclic axial loading analysis of piles in sand. J. Geotech. Engrg. 1989; 115(6): 836-852.

[31] Jardine, R. J. and Standing, J. R. Field axial cyclic loading experiments on piles driven in sand. Soils Found. 2012; 52(4): 723-736. 


\section{Tables and Figures}

\section{List of tables}

Table 1. A summary of the parametric study

Table 2. Parameters of the hypoplastic model and their values for Toyoura sand

Table 3. A summary of ultimate pile resistance, working load and mobilized shaft resistance and base resistance at working load

\section{List of figures}

Fig. 1. Verification of the hypoplastic model for prediction of sand volume change under cyclic shearing

Fig. 2. Shear stress - shear strain responses for test c: (a) Experimental results (from [14]); (b) Numerical results

Fig. 3. Stress ratio - dilatancy responses for test c: (a) Experimental results (from [14]); (b) Numerical results

Fig. 4. Dimensions and typical finite element mesh of the model domain

Fig. 5. (a) Applied amplitude of pile head displacement with loading cycles; (b)

Comparison between experimental results (from [29]) and numerical results

Fig. 6. Horizontal stress change and cumulative settlement of energy piles with thermal cycles

Fig. 7. (a) Shaft resistance reduction and base resistance mobilization with thermal cycles;

(b) Evolution of normalized shaft resistance and base resistance with thermal cycles

Fig. 8. Variations of stress and strain responses of soil elements adjacent to the energy pile with thermal cycles

Fig. 9. Effect of the amplitude of thermal cycles on the horizontal stress decrease after 50 thermal cycles

Fig. 10. Effect of the pile diameter on the horizontal stress decrease after 50 thermal cycles

Fig. 11. Effect of the pile length on the horizontal stress decrease after 50 thermal cycles 
Table 1. A summary of the parametric study

\begin{tabular}{|c|c|c|c|c|c|}
\hline $\begin{array}{c}\text { Series } \\
\text { No. }\end{array}$ & $\begin{array}{l}\text { Factor } \\
\text { studied }\end{array}$ & $L(\mathrm{~m})$ & $D(\mathrm{~m})$ & $\Delta T\left({ }^{\circ} \mathrm{C}\right)$ & $D_{\mathrm{r}}$ \\
\hline 1 & $\Delta T$ & 20 & 1.0 & $\begin{array}{l}\text { From } 5 \text { to } 20 \\
\text { at the interval } \\
\text { of } 2.5\end{array}$ & $25 \%, 55 \%, 85 \%$ \\
\hline 2 & $D$ & 20 & $\begin{array}{c}\text { From } 0.6 \text { to } \\
1.4 \text { at the } \\
\text { interval of } 0.2\end{array}$ & 15 & $25 \%, 55 \%, 85 \%$ \\
\hline $\begin{array}{l}3 \\
4\end{array}$ & $L$ & $\begin{array}{l}\text { From } 20 \text { to } 35 \\
\text { at the interval of } \\
5\end{array}$ & $\begin{array}{c}1.0 \\
L / D=20\end{array}$ & 15 & $55 \%$ \\
\hline
\end{tabular}


Table 2. Parameters of the hypoplastic model and their values for Toyoura sand

\begin{tabular}{|c|c|c|c|}
\hline & Parameter definition & $\begin{array}{c}\text { Parameter } \\
\text { symbol }\end{array}$ & $\begin{array}{c}\text { Parameter } \\
\text { value }\end{array}$ \\
\hline \multirow{8}{*}{$\begin{array}{c}\text { Parameters } \\
\text { included in von } \\
\text { Wolffersdorff's } \\
\text { model }\end{array}$} & Critical state friction angle & $\varphi_{\mathrm{c}}^{\prime}$ & $31^{\circ}$ \\
\hline & $\begin{array}{c}\text { Extrapolated maximum void ratio } \\
\text { at vanishing pressure }\end{array}$ & $\mathrm{e}_{\mathrm{i} 0}$ & 1.10 \\
\hline & $\begin{array}{c}\text { Extrapolated minimum void ratio } \\
\text { at vanishing pressure }\end{array}$ & $\mathrm{e}_{\mathrm{d} 0}$ & 0.61 \\
\hline & $\begin{array}{l}\text { Extrapolated critical state void ratio } \\
\text { at vanishing pressure }\end{array}$ & $\mathrm{e}_{\mathrm{c} 0}$ & 0.98 \\
\hline & Parameters controlling & $h_{\mathrm{s}}$ & $2.6 \mathrm{GPa}$ \\
\hline & the isotropic compression line & $n$ & 0.27 \\
\hline & $\begin{array}{c}\text { Parameter affecting } \\
\text { the peak strength ratio }\end{array}$ & $\alpha$ & 0.14 \\
\hline & $\begin{array}{l}\text { Parameter affecting } \\
\text { the incremental stiffness }\end{array}$ & $\beta$ & 1.1 \\
\hline \multirow{6}{*}{$\begin{array}{l}\text { Additional } \\
\text { parameters for } \\
\text { Niemunis and } \\
\text { Herle's model }\end{array}$} & $\begin{array}{l}\text { Parameter controlling } \\
\text { the initial shear stiffness } \\
\text { upon } 180^{\circ} \text { reversal of strain path }\end{array}$ & $m_{\mathrm{R}}$ & 11 \\
\hline & $\begin{array}{l}\text { Parameter controlling } \\
\text { the initial shear stiffness }\end{array}$ & $m_{\mathrm{T}}$ & 6 \\
\hline & upon $90^{\circ}$ reversal of strain path & & \\
\hline & Size of the inter-granular strain & $R$ & $2 \times 10^{-5}$ \\
\hline & $\begin{array}{l}\text { Parameter controlling the } \\
\text { evolution of inter-granular strain }\end{array}$ & $\beta_{\mathrm{r}}$ & 0.1 \\
\hline & $\begin{array}{l}\text { Parameter controlling the stiffness } \\
\text { degradation with strain }\end{array}$ & $\chi$ & 1.0 \\
\hline
\end{tabular}


Table 3. A summary of ultimate pile resistance, working load and mobilized shaft resistance and base resistance at working load

\begin{tabular}{|c|c|c|c|c|c|c|c|c|c|c|c|c|}
\hline$L(\mathbf{m})$ & $D(\mathbf{m})$ & $D_{\mathrm{r}}$ & $Q(\mathbf{k N})$ & $P(\mathbf{k N})$ & $Q_{\mathrm{s}}(\mathbf{k N})$ & $Q_{\mathrm{B}}(\mathbf{k N})$ & $\left(Q_{\mathrm{s}}\right)^{\mathbf{p}}(\mathbf{k N})$ & $\left(Q_{\mathrm{B}}\right)^{\mathrm{p}}(\mathbf{k N})$ & $\begin{array}{c}\left(Q_{\mathrm{s}}\right)^{\mathrm{p}} / Q_{\mathrm{s}} \\
(\%)\end{array}$ & $\begin{array}{c}\left(Q_{\mathrm{B}}\right)^{\mathrm{p}} / Q_{\mathrm{B}} \\
(\%)\end{array}$ & $\begin{array}{c}\left(Q_{\mathrm{s}}\right)^{\mathrm{p}} / P \\
(\%)\end{array}$ & $\begin{array}{c}\left(Q_{\mathrm{B}}\right)^{\mathrm{p}} / P \\
(\%)\end{array}$ \\
\hline \multirow{15}{*}{20} & 0.6 & & 1663 & 832 & 1444 & 219 & 779 & 53 & 54 & 24 & 94 & 6 \\
\hline & 0.8 & & 2343 & 1172 & 1950 & 393 & 1077 & 95 & 55 & 24 & 92 & 8 \\
\hline & 1.0 & $25 \%$ & 3093 & 1547 & 2460 & 633 & 1416 & 131 & 58 & 21 & 92 & 8 \\
\hline & 1.2 & & 3903 & 1951 & 2977 & 926 & 1843 & 108 & 62 & 12 & 94 & 6 \\
\hline & 1.4 & & 4791 & 2395 & 3500 & 1291 & 2168 & 227 & 62 & 18 & 91 & 9 \\
\hline & 0.6 & & 1972 & 986 & 1589 & 383 & 895 & 91 & 56 & 24 & 91 & 9 \\
\hline & 0.8 & & 2816 & 1408 & 2134 & 682 & 1273 & 135 & 60 & 20 & 90 & 10 \\
\hline & 1.0 & $55 \%$ & 3765 & 1883 & 2685 & 1080 & 1705 & 178 & 63 & 16 & 91 & 9 \\
\hline & 1.2 & & 4807 & 2404 & 3247 & 1560 & 2146 & 258 & 66 & 17 & 89 & 11 \\
\hline & 1.4 & & 5963 & 2982 & 3818 & 2145 & 2662 & 320 & 70 & 15 & 89 & 11 \\
\hline & 0.6 & & 2425 & 1212 & 1779 & 646 & 1058 & 154 & 59 & 24 & 87 & 13 \\
\hline & 0.8 & & 3543 & 1772 & 2367 & 1176 & 1557 & 215 & 66 & 18 & 88 & 12 \\
\hline & 1.0 & $85 \%$ & 4823 & 2412 & 2966 & 1857 & 2057 & 355 & 69 & 19 & 85 & 15 \\
\hline & 1.2 & & 6270 & 3135 & 3582 & 2688 & 2629 & 506 & 73 & 19 & 84 & 16 \\
\hline & 1.4 & & 7890 & 3945 & 4201 & 3689 & 3290 & 655 & 78 & 18 & 83 & 17 \\
\hline 25 & \multirow{3}{*}{1.0} & \multirow{3}{*}{$55 \%$} & 5408 & 2704 & 4177 & 1231 & 2513 & 191 & 60 & 16 & 93 & 7 \\
\hline 30 & & & 7365 & 3683 & 5987 & 1378 & 3454 & 229 & 58 & 17 & 94 & 6 \\
\hline 35 & & & 9641 & 4820 & 8134 & 1507 & 4640 & 180 & 57 & 12 & 96 & 4 \\
\hline 25 & 1.25 & \multirow{3}{*}{$55 \%$} & 7201 & 3600 & 5262 & 1939 & 3340 & 260 & 63 & 13 & 93 & 7 \\
\hline 30 & 1.5 & & 12246 & 6123 & 9110 & 3136 & 5627 & 496 & 62 & 16 & 92 & 8 \\
\hline 35 & 1.75 & & 19207 & 9603 & 14473 & 4734 & 8921 & 682 & 62 & 14 & 93 & 7 \\
\hline
\end{tabular}

Notes: $L$ - Pile length; $D$ - Pile diameter; $D_{\mathrm{r}}$ - Relative density; $Q$ - Ultimate pile resistance; $P$ - Working load; $Q_{\mathrm{s}}-$ Ultimate shaft resistance; $Q_{\mathrm{B}}-$ Ultimate base resistance; $\left(Q_{\mathrm{s}}\right)^{\mathrm{p}}-$ Mobilized shaft resistance at working load; $\left(Q_{\mathrm{B}}\right)^{\mathrm{p}}-$ Mobilized base resistance at working load. 
(a)
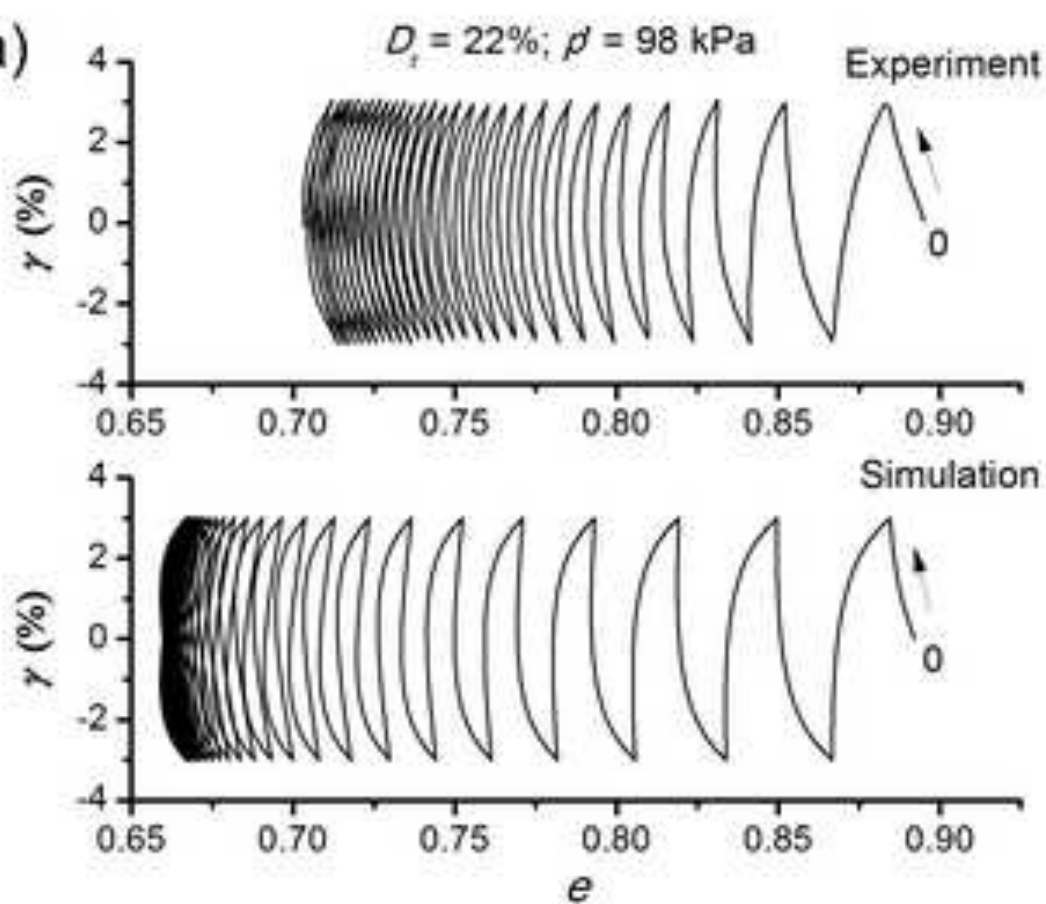

(c)
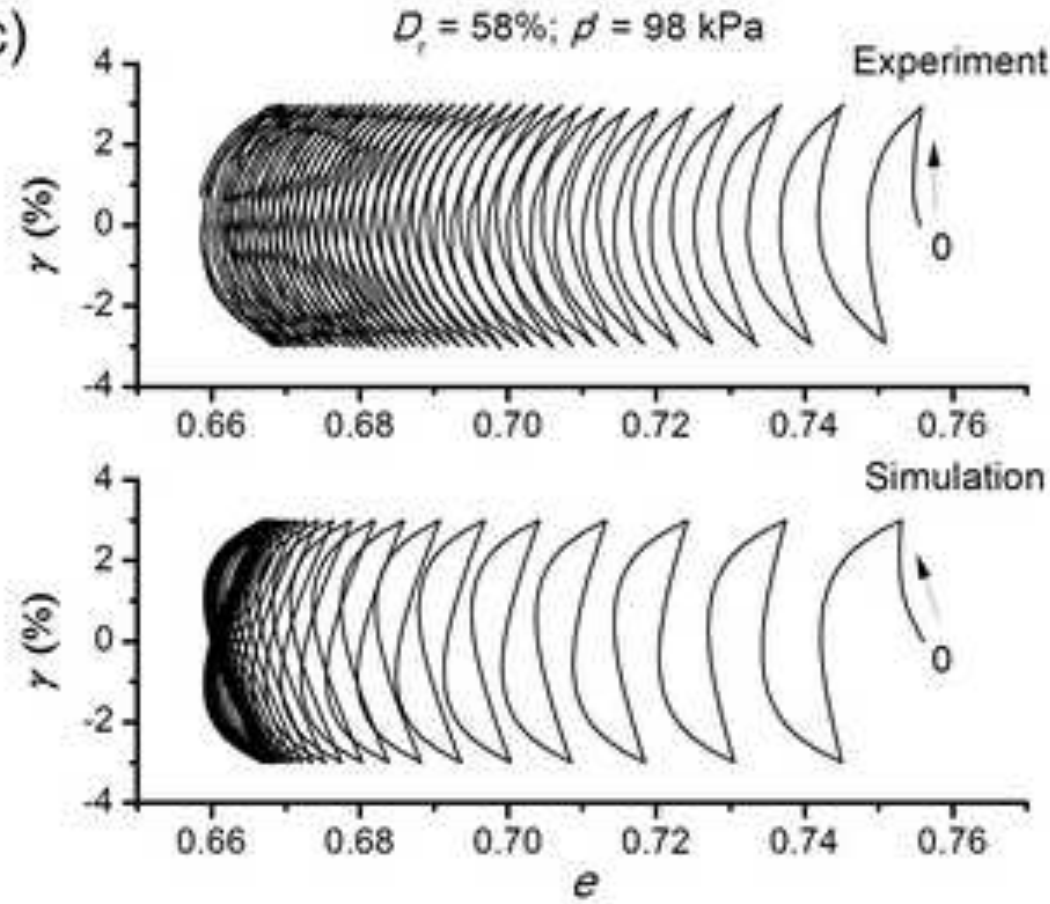

(b)
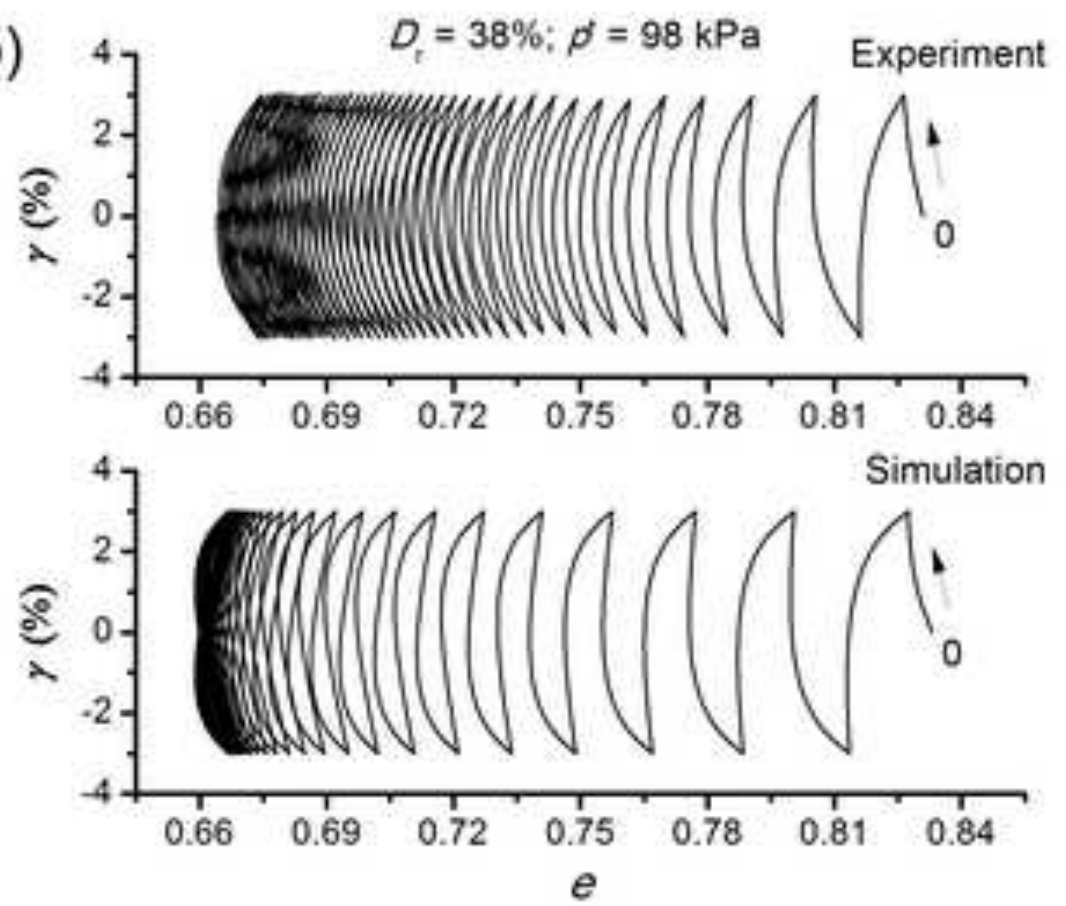

(d)
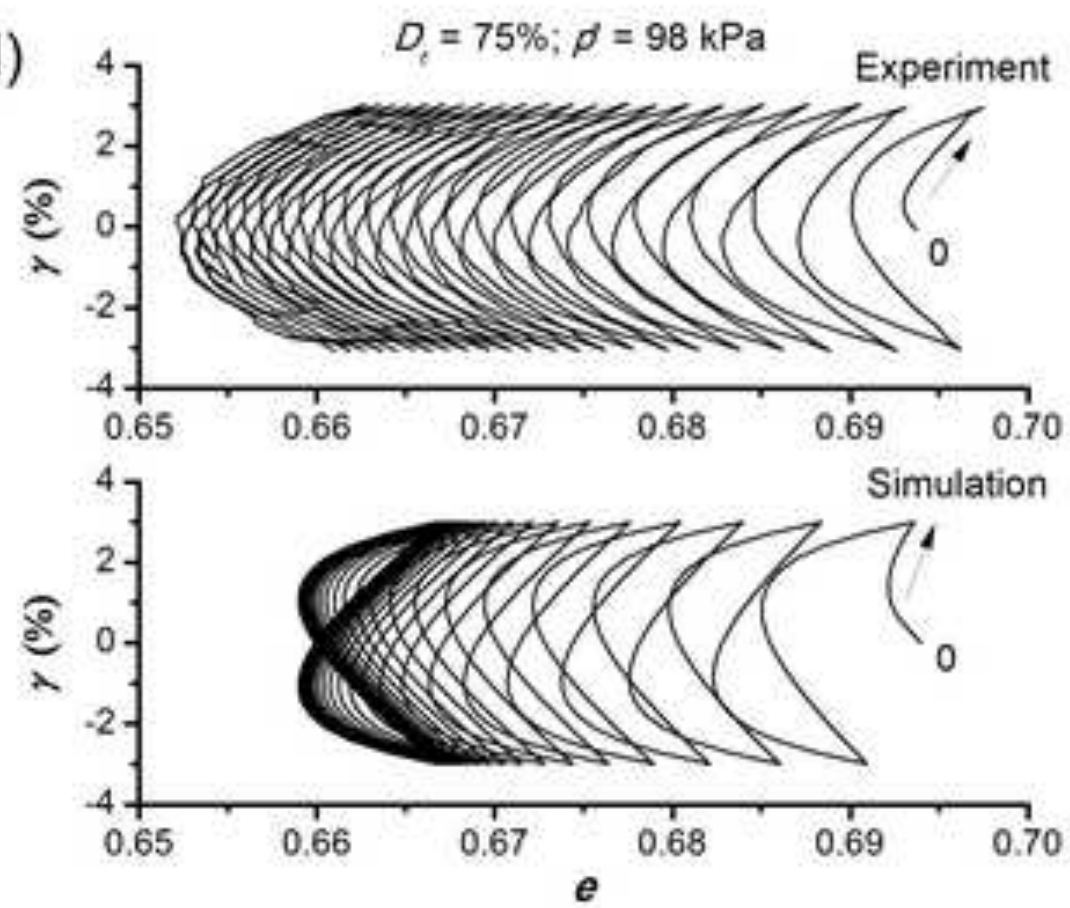
(a)

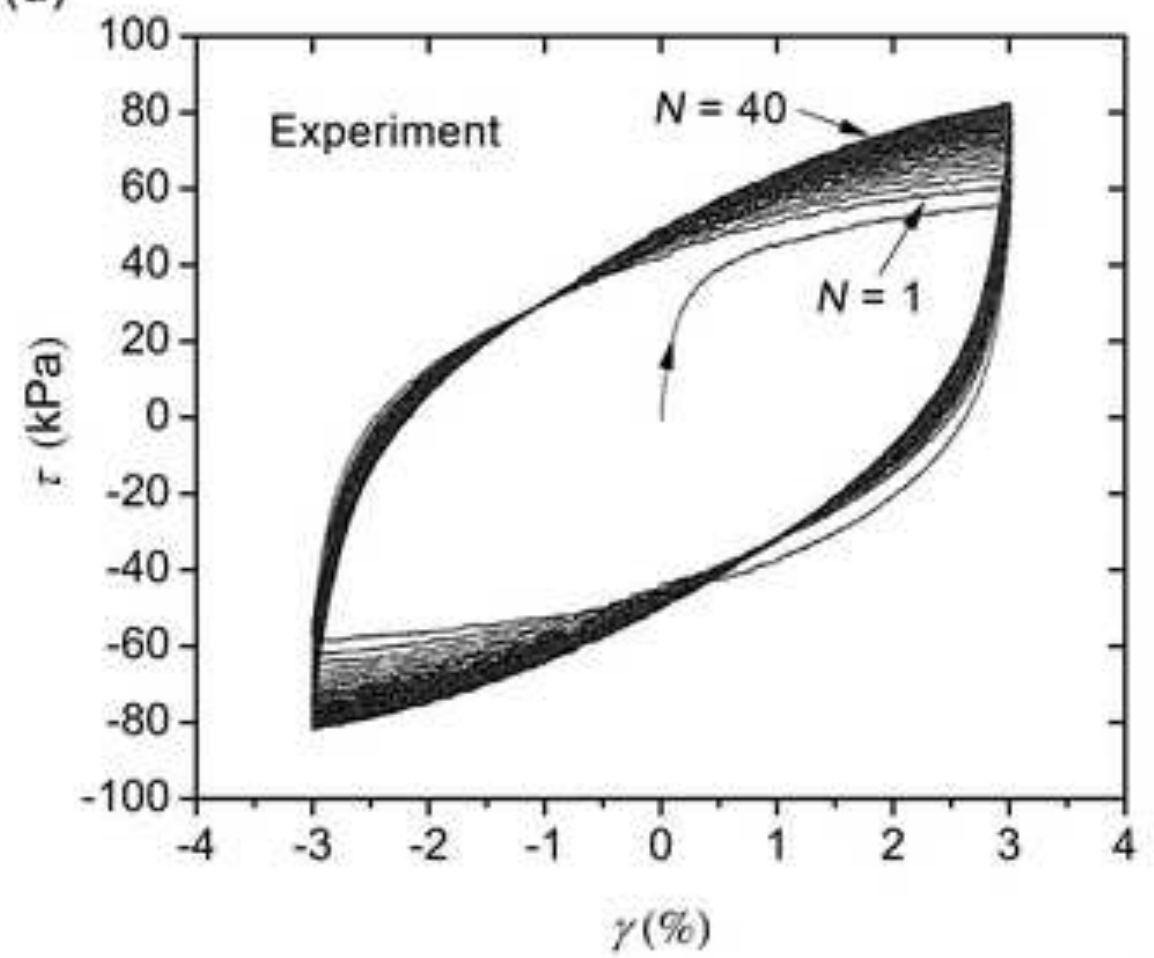

(b)

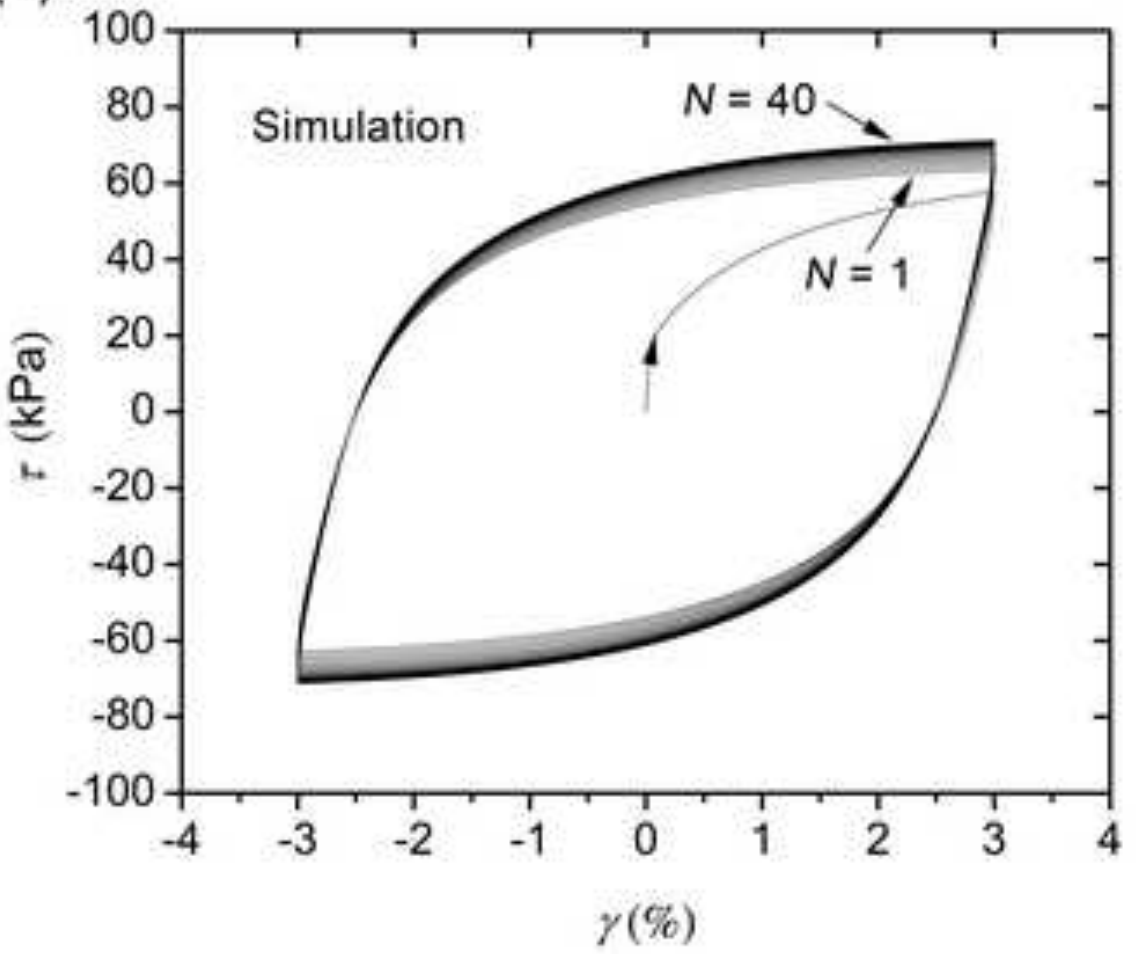


(a)

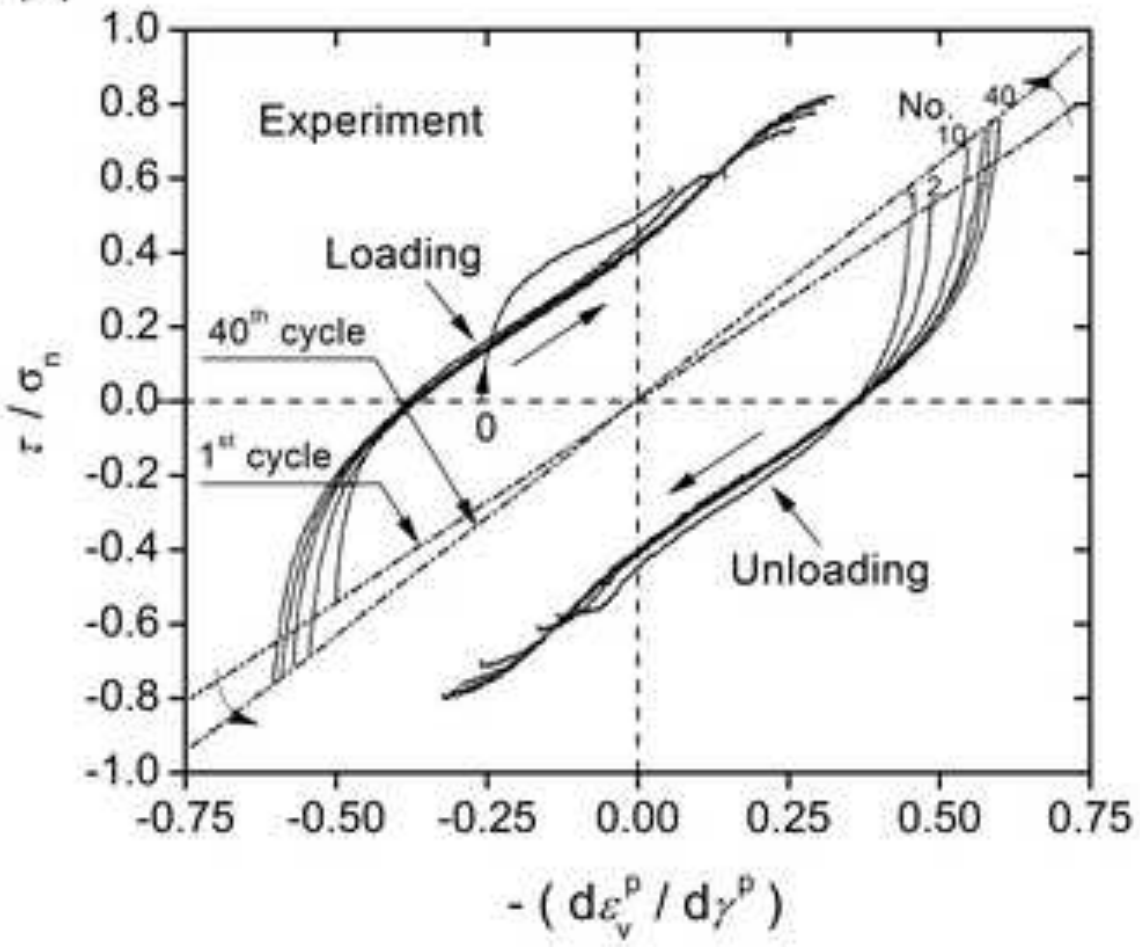

(b)

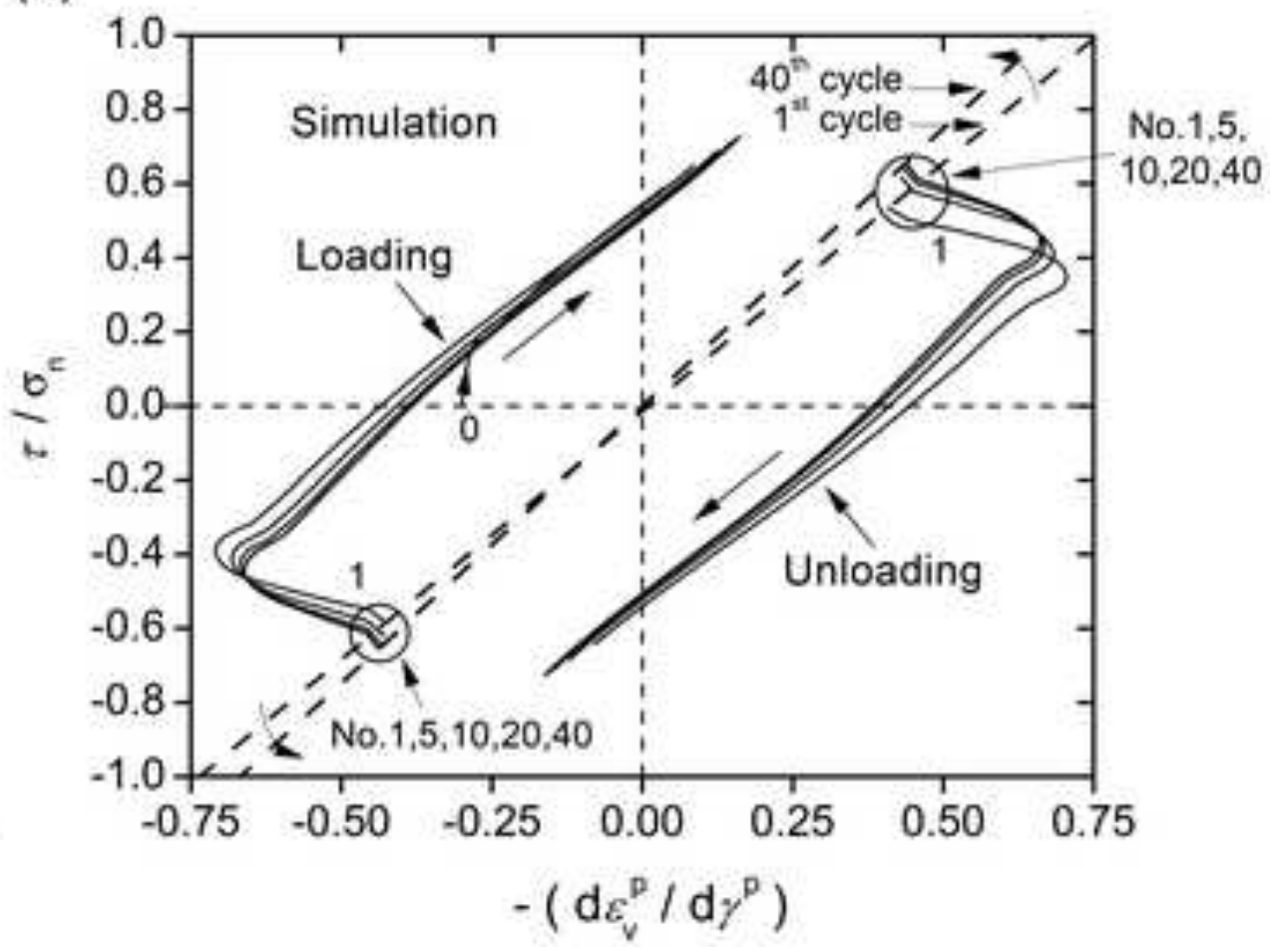




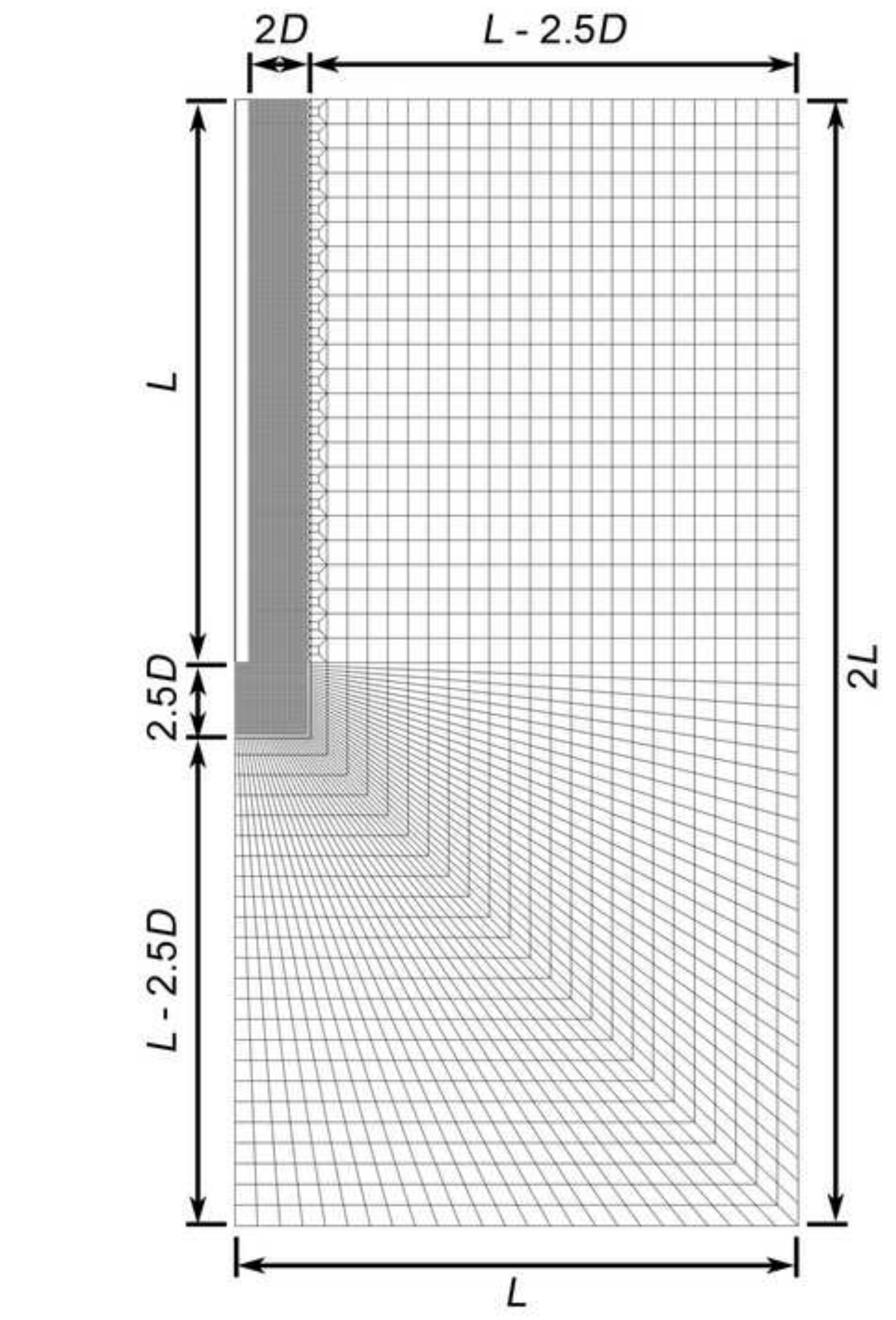

Figure 4
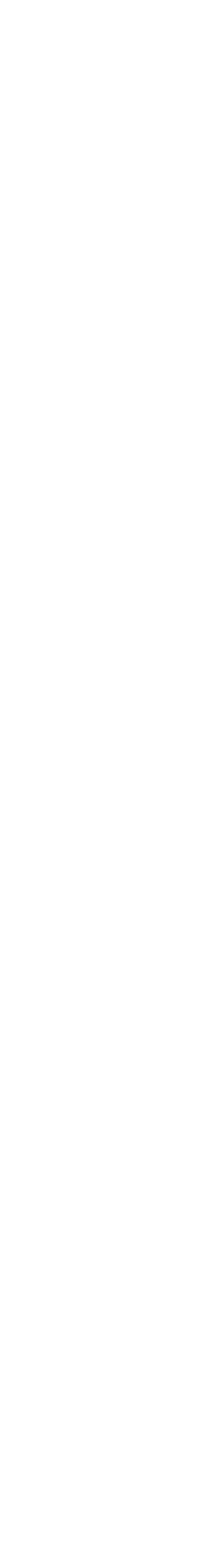

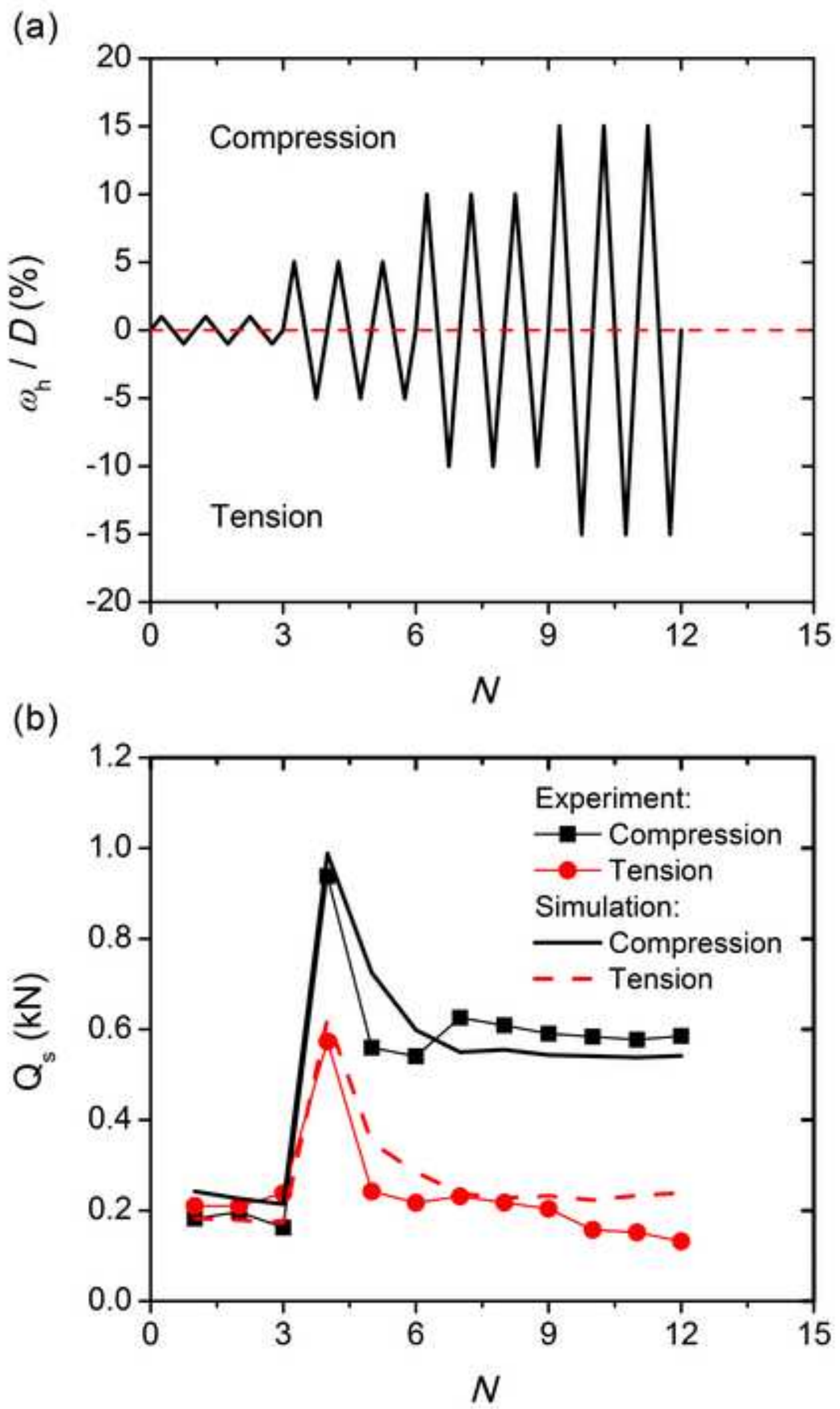

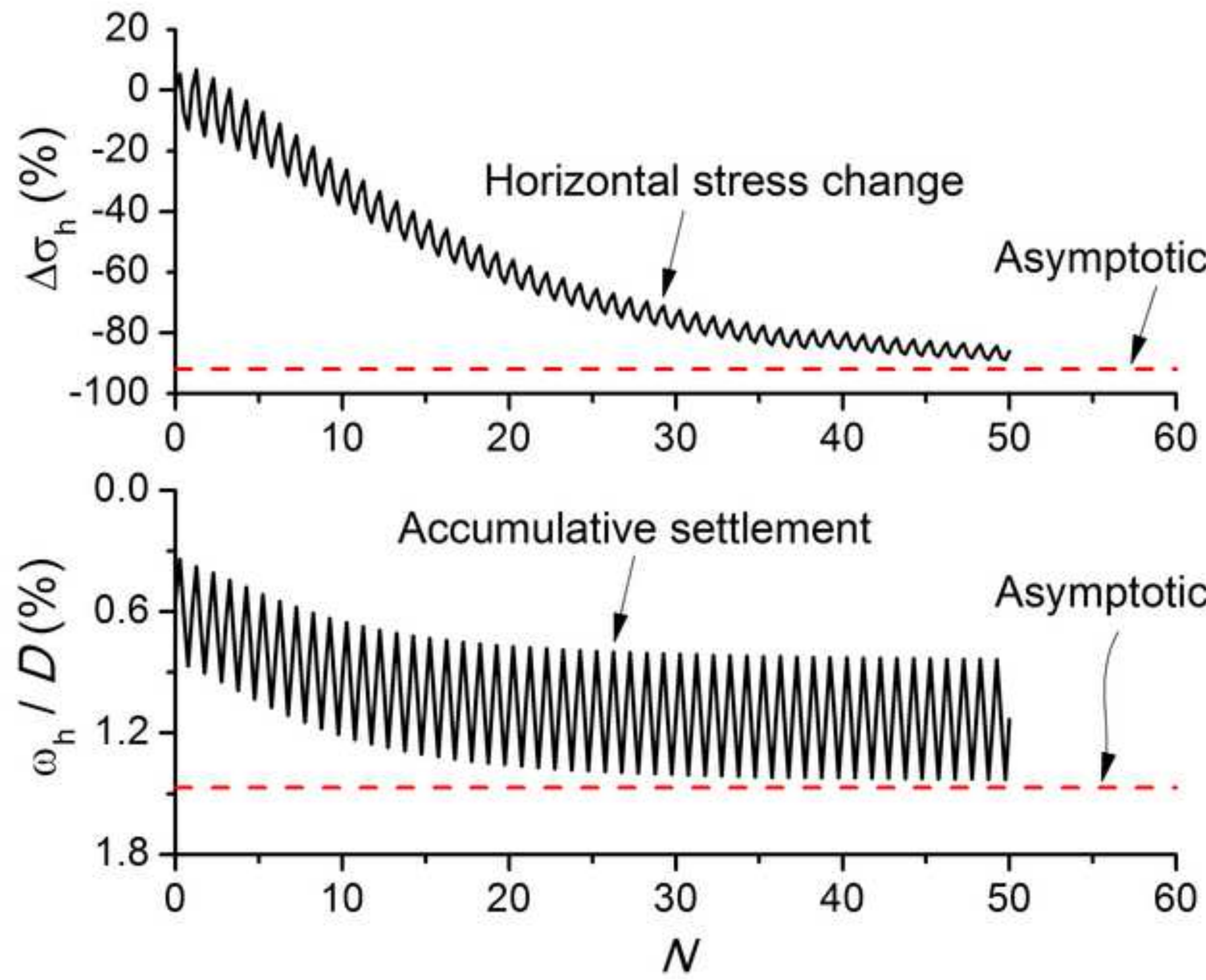
(a)

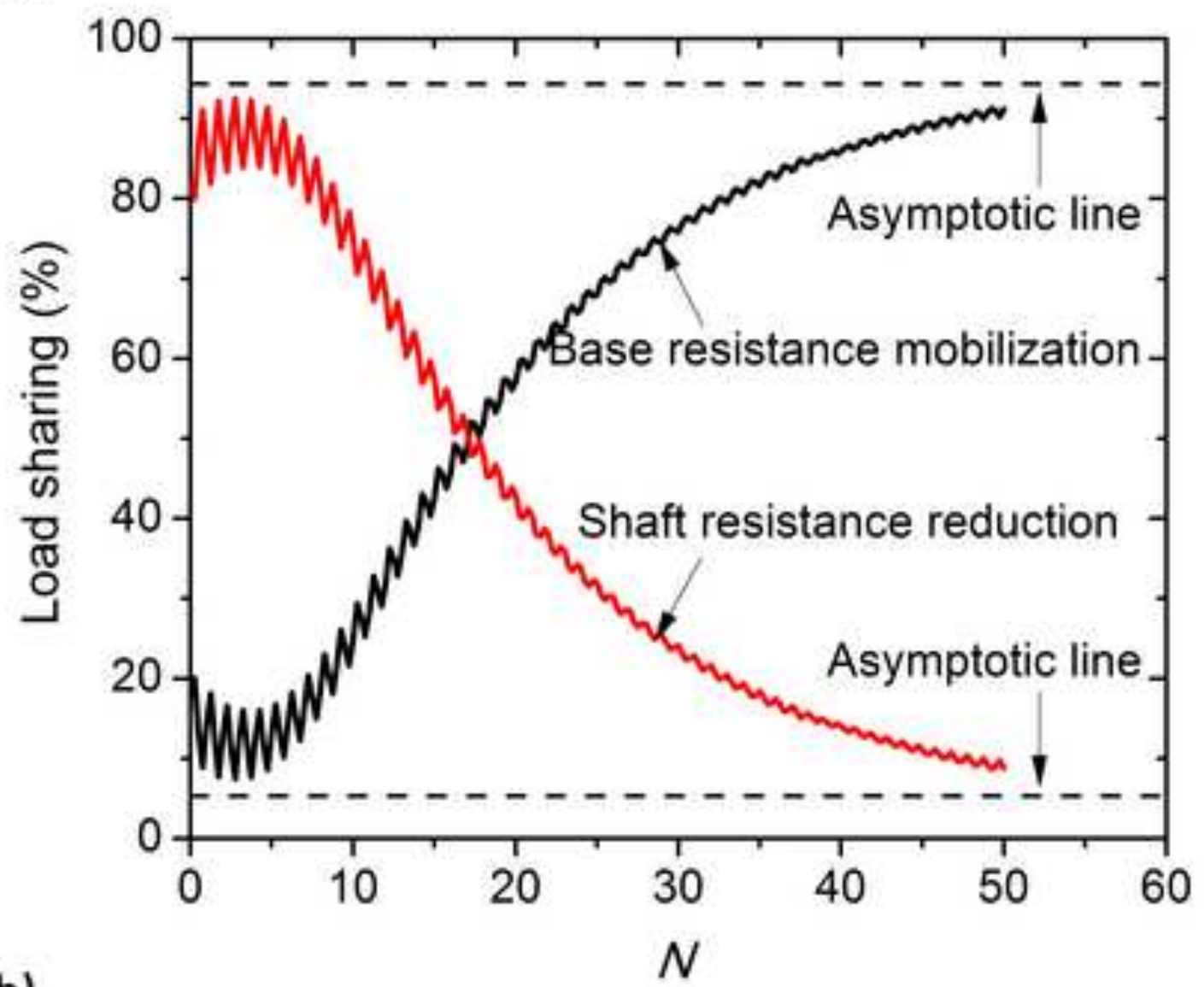

(b)

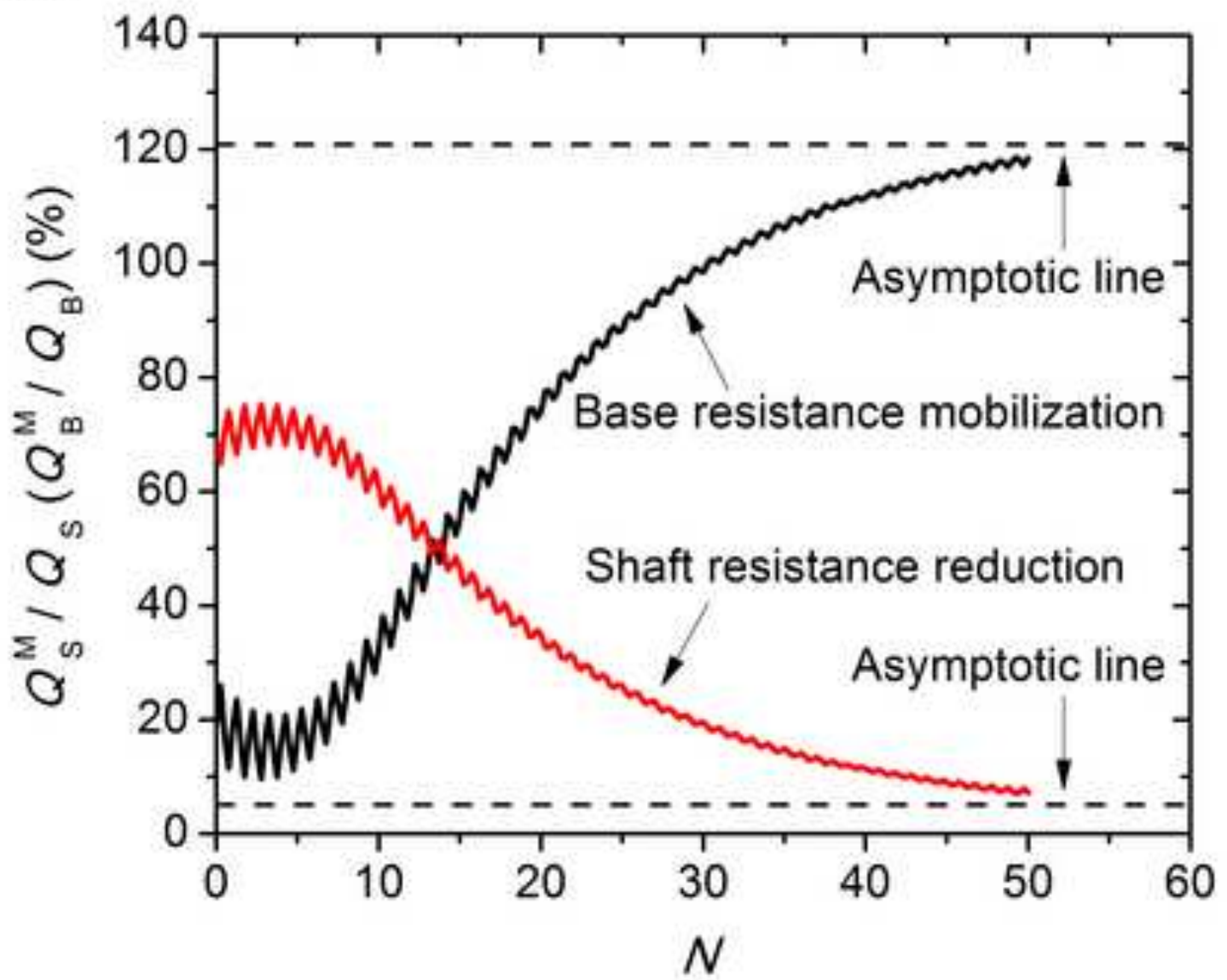




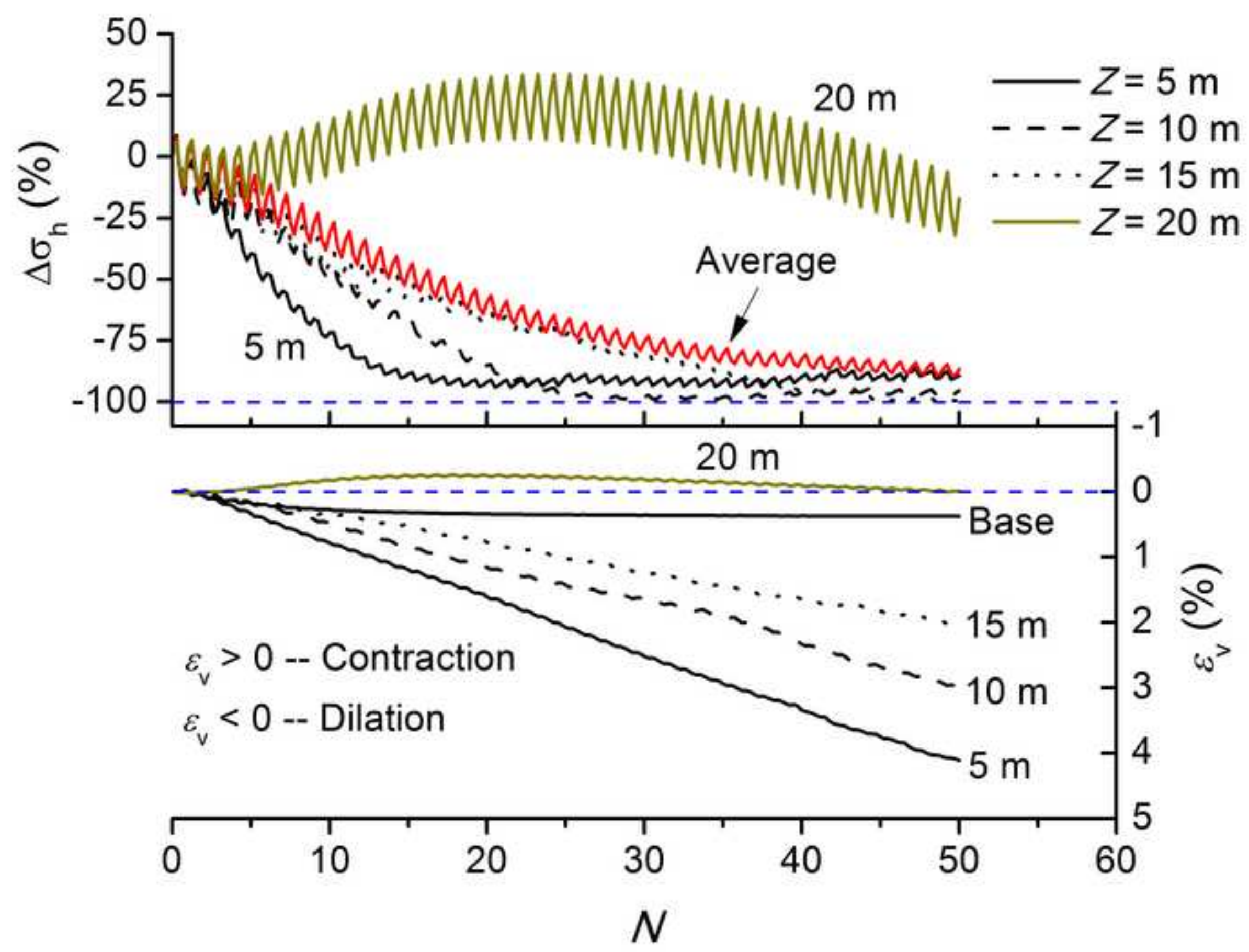




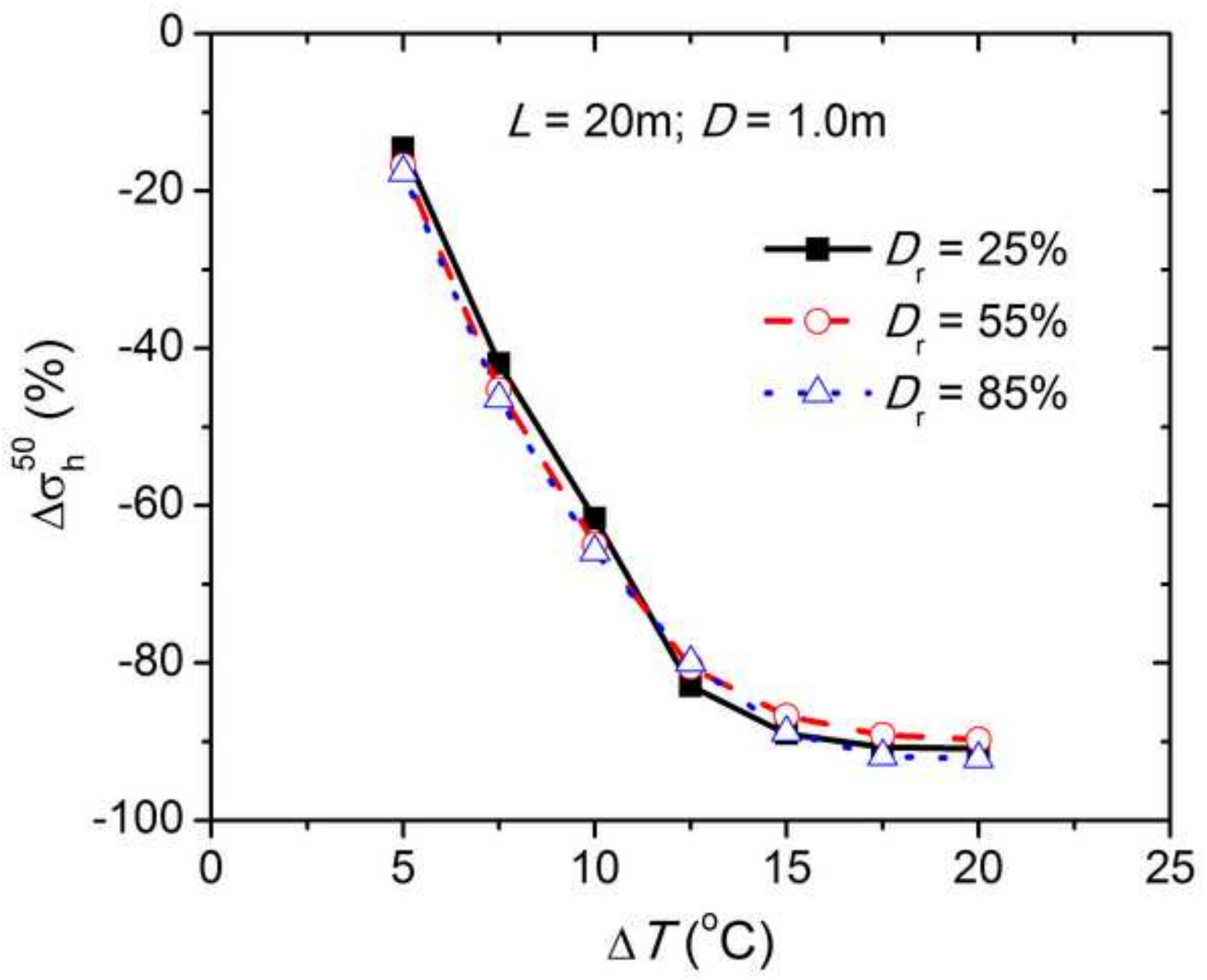




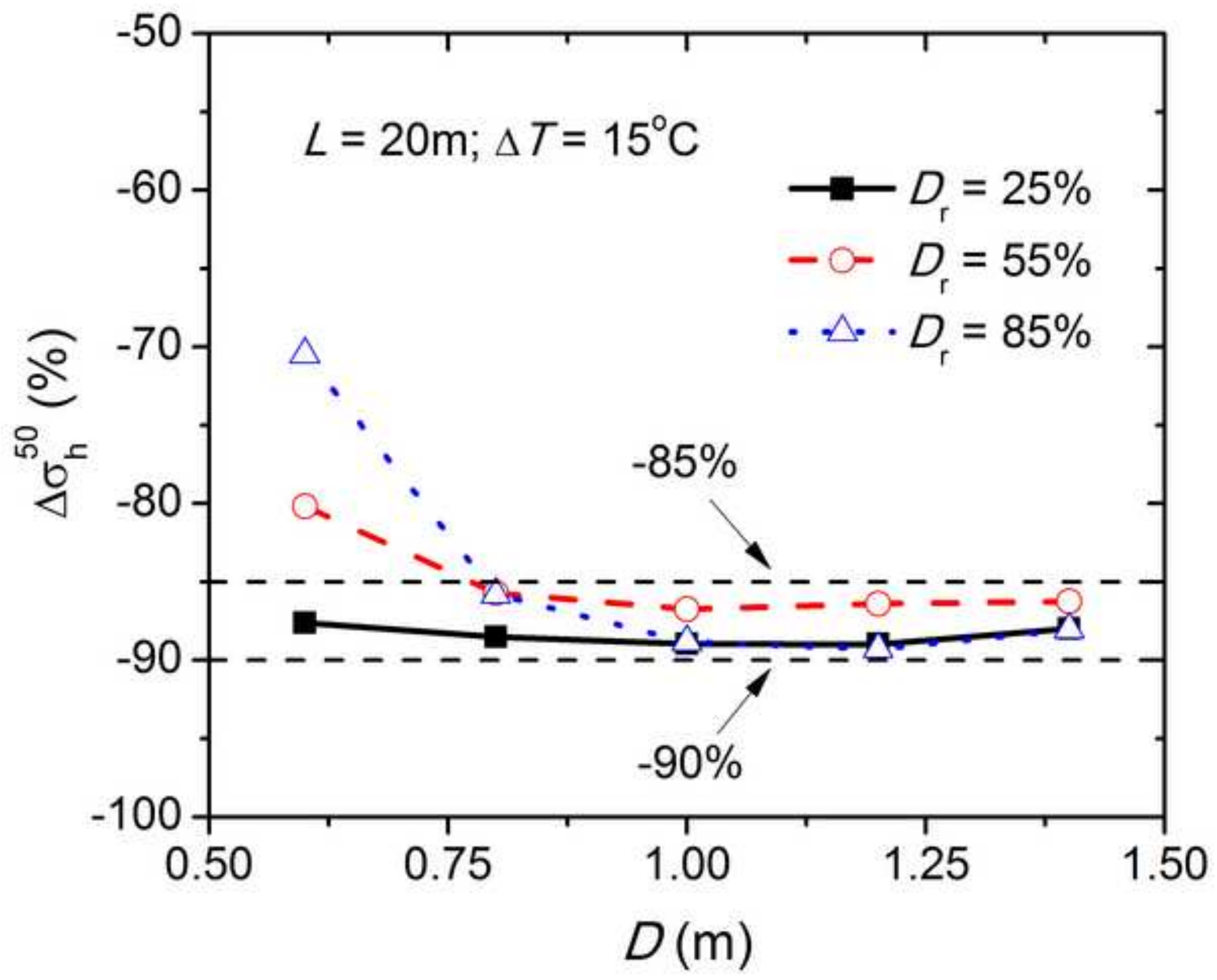




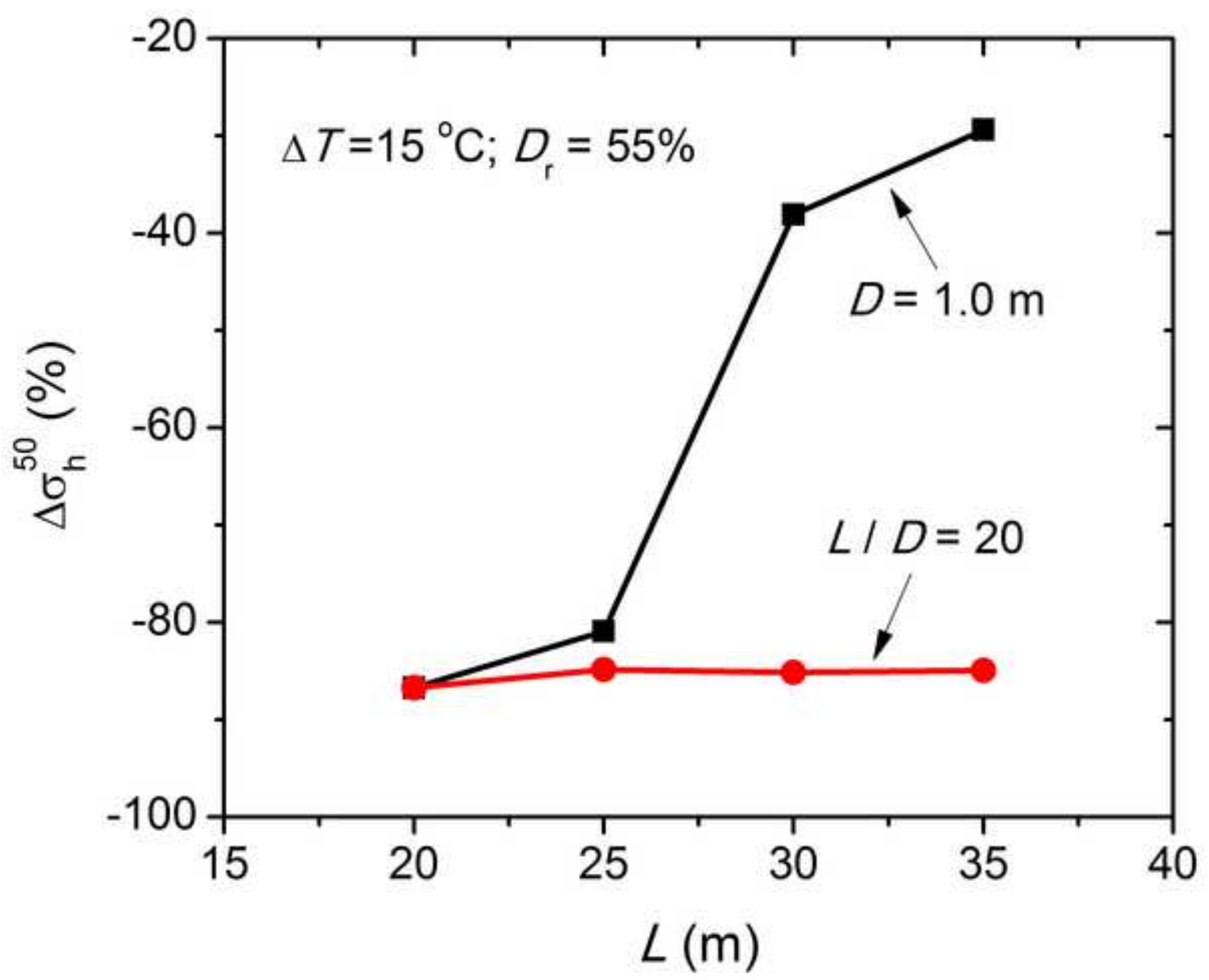

